\title{
Royal Society of Medicine
}

child's first year, for the bulk of these cases took their origin in the years between birth and 5. Recently he had seen a good many recruits for the Services who had been rejected because of running ears, and it had been brought home to him that between school-leaving age at I4 and entering national health insurance they had received no treatment.

Mr. J. C. Hogg said that during the past twelve years he had been aural surgeon to elementary school clinics on the outskirts of London, and for seven years he had been seeing cases referred from the welfare centres run by the urban district council. It was found that the incidence of otitis media had considerably decreased among the elementary school children of that area. The mothers were becoming educated to take their infant children to the welfare centre for advice, and again in many cases the medical officers attached to those welfare centres were now on the look-out for otitis media. They referred such cases to the school centre, where they were examined, and he was glad to say that he did not believe that there had been during the last seven years any cases of acute otitis media among infants which had failed to respond to conservative measures. In this particular school centre" the children were examined by the assistant school medical officers on entry, that is, at the age of 5 , when they were sorted out, and all ear, nose and throat cases were referred to a specialist. They were examined again at the age of Io, and the cases which called for such a course were referred again to the specialist, and at the school-leaving age they were once more examined and referred if necessary.

He agreed with Mr. Mollison that the gap between school-leaving age at I4 and at the age at which these persons became eligible for the Services was a serious one. The records of the militia boards showed that these cases had had treatment at school, but nothing had been done since leaving.

\section{ABSTRACTS}

\section{BRONCHI.}

Bronchoscopy in the diagnosis and treatment of Bronchiectasis in Children. Dr. D. E. S. Wishart (Toronto). Jour. A.M.A., December, I942, cxx. Bronchography for the purpose of demonstrating the location and severity of bronchiectatic lesions has been used at the Hospital for Sick Children, Toronto, since December 1927. The technique is given in detail and the results are described in this paper.

Iodized poppy seed oil is put into the bronchial tree by the bronchoscope under general anæsthesia. Bronchiectasis now is frequently diagnosed and the number of cases labelled as either chronic bronchitis or unresolved bronchopneumonia has become proportionately less. Children of every age from infancy upward and with the severest types of bronchiectasis have been investigated and treated. Patients under 2 years of age have been bronchographed and under I year of age have been suctioned without any complication. The bronchography under general anæsthesia and without sedative is performed on a fluoroscopic table and thus the injection of iodized oil can 


\begin{abstract}
be followed by radiologist, attending physician and bronchoscopist. Prolonged adequate evacuation of the bronchial secretions is essential. The mere introduction of iodized oil into the bronchial tree is not sufficient. The oil must reach the diseased portion of the bronchi in sufficient but not too great quantity and remain there long enough to allow the radiologist to make the necessary exposures. The total number of embarrassing complications following $I, 275$ lipiodol injections or suctions in bronchiectatic cases was seven. Only one death that can be ascribed to injection of oil occurred in the entire series. Overfilling of any part of the lung renders the radiogram useless for visualization. Fallacies to be avoided; contra-indications, surgical cures by lobectomy; the pathological conditions found; are discussed. The treatment of bronchiectasis in children is described in some detail.

The author believes that bronchoscopy, together with bronchoscopic suction, injection of iodized. oil under general anæsthesia and bronchogram has proven of unquestioned benefit in the study and treatment of bronchiectasis in children. These procedures determine which children are suitable for the only cure known-major surgery. These preliminary studies disclose the cases where major surgery is contra-indicated. The degree of the existing disease is ascertained. Bronchoscopy provides the most effective form of of treatment of the large group which do not require major surgery. Bronchography permits the early definite diagnosis of the disease and, therefore, affords the great hope that the further progress of a most devastating disease can be checked.

Angus A. Campbell.
\end{abstract}

\title{
LARYNX.
}

Cancer of the Larynx. Max Cutler, M.D. (Chicago). Jour. A.M.A., October Igth, I940, $\mathrm{cxv}$, no. I6.

The writer bases this communication on three hundred cases seen during the last ten years. A "radiosensitive" tumour is defined as one that can be completely sterilized without damage to the surrounding normal tissues. It is almost impossible to draw a fine line between "radiosensitive" and " radioresistant" tumours.

Cancer of the larynx is divided into four types: (I) laryngeal vestibule (epiglottis, false cord), (2) ventricular cavity, (3) vocal cord, (4) subglottic area.

Six illustrative cases are reported describing the lesions and results of treatment. The microscopic structure of a biopsy specimen is of some help in estimating prognosis and in guiding treatment. Its value, however, is distinctly limited and unless the microscopic changes are interpreted in the light of clinical and gross anatomical factors the biopsy alone may be highly misleading. The specimen taken for biopsy may not be representative of the actual lesion. This error may be diminished by taking specimens from different portions of the lesion. When biopsy discloses a highly undifferentiated carcinoma it may be assumed that the lesion is of this type, but the contrary is not true. If the biopsy shows a highly undifferentiated carcinoma, the radiosensitivity of the lesion may be predicted with reasonable certainty but its radiocurability is dependent on the extent of the disease, the general condition of the patient, efficiency of the treatment and other factors of a biological nature which are not understood. 


\section{Nose}

Carcinoma arising in the false cords and epiglottis is generally undifferentiated and radiosensitive. Carcinoma arising in the true cord is generally differentiated, and its radiosensitivity depends on the presence or absence of invasion of other tissues.

Mobility of the lesion and the surrounding structures is a most important clinical sign and is the most important indication of radiosensitivity. Radiosensitivity of carcinoma of the larynx cannot be determined on the basis of microscopic structure alone.

The article is freely illustrated and has a bibliography.

\section{Angus A. Campbell.}

NOSE.

Normal and abnormal Bacterial Flora of the Nose. LEON ORRIS JACOBSON, M.D. and George F. Dick, M.D. Jour. A.M.A., December 27th, I94I, cxvii, no. 26.

The writers base their studies on cultures from the nasal secretion from five hundred consecutive patients admitted to the general medical ward. None of these patients was admitted because of a primary complaint in the nose or para-nasal sinuses.

The normal nasal flora consists chiefly of staphylococcus albus and diphtheroid bacilli with staphylococcus aureus and micrococcus catarrhalis less frequently. The presence of streptococci, pneumococci, bacillus mucosus, Pfeiffer bacilli and diphtheria bacilli indicates disease of the nasal mucosa, sinus disease or both.

Green forming streptococci and pneumococci are occasional transients of the nasal cavity. The frequency with which green forming streptococci, haemolytic streptococci and pneumococci were isolated by culture of nasal secretion in acute or chronic sinusitis shows the diagnostic value of this simple and inexpensive procedure.

The article has five tables and a bibliography.

Augus A. Campbell.

\section{MISCELLANEOUS.}

Vitamins for the. Prevention of Colds. Donald W. Cowan, M.D., Harold S. Diehl, M.D. and A. B. Baker, M.D. (Minneapolis). Jour. A.M.A., December Igth, I942, cxx!, no. I6.

During the school year I939-I940, four hundred and twenty-seven students were enrolled in the "cold prevention group". In order to exclude from the study persons whose difficplties seemed to be due primarily to chronic sinusitis or allergic rhinitis, special attention was paid to the nose and throat and to symptoms suggestive of allergy.

One group of students was given tablets of synthetic ascorbic acid while the control group was given placebos. The ones who took the vitamin $\mathrm{C}$ supplement had a slight advantage ( 3 per cent.) in reducing the number of colds. On the other hand they had more complications such as bronchitis, otitis and sinusitis than those in the control group. 


\section{Abstracts}

During the school year I940-I94I, two hundred and sixty-four students were divided into similar groups. These were given multiple vitamins containing $\mathrm{A}, \mathrm{B}, \mathrm{B} 2, \mathrm{C}$ and $\mathrm{D}$ and nicotinic acid. From the tabled results no evidence was revealed that multiple vitamins reduced the severity of colds. The average duration of each cold was the same for both groups and complications were more frequent among the students who got the vitamin supplements than in the control group.

The students were presumed to be on a reasonably adequate diet.

Augus A. Campbell.

Pulmonary Tuberculosis masquerading as Laryngitis. JOSEPH C. DONNELLY, M.D. (Philadelphia). Jour. A.M.A., October 3Ist, I942, cxx, no. 9.

When a patient complains of chronic hoarseness or sore throat, pulmonary tuberculosis should always be in the mind of the physician. A critical analysis of twenty-six patients shows that the laryngeal symptoms were the first manifestations of pulmonary disease. The chief misleading factor is the apparent well being of the patient whose latent pulmonary and systemic signs are masked by laryngeal symptoms.

Unfortunately laryngitis is not a sign of early tuberculosis since several cases showed far-advanced pulmonary lesions several weeks after the initial onset of the laryngeal symptoms.

The presence of ulceration or odema is a bad sign, while the finding of a tuberculoma signifies a favourable prognosis. The prognos is isdefinitely better when only the interior of the larynx is involved.

The article is illustrated, has four tables and a bibliography.

Augus A. Campbell. 